\title{
MATERNAL OUTCOME IN PATIENTS WITH DIABETES MELLITUS IN PREGNANCY
}

\section{Dr. Shailendra Gupta}

Dr. Rohitash Kularia

Dr.Subash Chandra

Dr. Anita Sharma*

\section{Resident Doctor, Department of General medicine, Sardar Patel Medical} College, Bikaner

Associate professor, Department of General medicine, Sardar Patel Medical College, Bikaner

Associate professor, Department of General medicine, Sardar Patel Medical College, Bikaner

Associate professor, Department of Obstetrics and Gynecology, S. P. Medical College, Bikaner ${ }^{*}$ Corresponding Author

ABSTRACT Background- The study was conducted to review Maternal outcome in pregnancy with diabetes and to plan management of pregnancy with diabetes and to study the modalities for treatment of DM in

pregnancy.

Methods- A prospective case study was conducted at SPMC Bikaner. Study group used single step $75 \mathrm{gm}$ oral glucose tolerance test (OGTT) test recommended by WHO for GDM diagnosis.

Results- $45 \%$ patients had polyhydramnios and $38 \%$ developed preeclampsia. Preterm labor was common in $23 \%$ of GDM patients.

Conclusions- There was significant fetomaternal morbidity in patients with diabetes mellitus. Early diagnosis and treatment reduces the Maternal outcome.

\section{KEYWORDS :Maternal outcome, Gestational diabetes mellitus, Glycemic control.}

\section{INTRODUCTION}

Gestational diabetes mellitus (GDM) is defined as any degree of glucose intolerance with the onset or first time recognized during pregnancy with or without remission after the end of pregnancy.

Women with gestational diabetes are characterized to have a relatively diminished insulin secretion and pregnancy induced insulin resistance primarily present in the skeletal muscle tissue. Normal pregnancy is considered to be a diabetogenic state characterized by exaggerated amount of insulin release, associated with decreased sensitivity to insulin at cellular levels. These changes are results of the progressive rise in the levels of estrogen, progesterone, human placental lactogen, cortisol and prolactin as pregnancy advances. Many of these hormones are insulin antagonists which causes insulin resistance in the mother and cause abnormal glucose tolerance in some women rendering them to develop gestational diabetes. ${ }^{2}$

The magnitude of GDM varies according to the country and the ethical groups. The life style, educational status, family history of diabetes and other factors play an important role.Based on National Diabetes Data Group criteria, the percentage of women who develop GDM was $4 \%$. However, the fourth international workshop conference on Gestational Diabetes showed that the percentage of pregnant women developing GDM increased to $7 \%$ resulting in more than 200,000 cases annually. ${ }^{3}$

Maternal complications in GDM include increased incidence of asymptomatic bacteriuria, urinary tract infections, increased incidence of pre- eclampsia, polyhydramnios which may increase the incidence of preterm labor, placental abruption and post-partum hemorrhage and increased risk of operative delivery. The various fetal complications include intra uterine death, macrosomia, shoulder dystocia, increase incidence of respiratory distress syndrome, hypoglycemia, hypocalcemia, congenital malformations, polycythemia, hyperbilirubinemia. Long term complications include obesity, development of type 2 diabetes mellitus during childhood, impaired motor functions and higher rates of in attention deficit syndrome.

\section{MATERIAL AND METHODS}

This study was carried in the Department of Obstetrics and Gynecology Sardar Patel Medical College, Bikaner. 100 patients with DM with pregnancy who were in criteria were studied for feto-maternal outcome due to DM. Informed consent was taken from all the patients. Detailed history was taken including age, gestational age, history of still birth or pregnancy loss, family history of diabetes, past history of diabetes, obstetric history. Detailed examination was done. Various parameters noted were mode of delivery, fetal weight, maternal and neonatal complications, and neonatal intensive care admission. Data were analyzed by Epi-info software.

\section{RESULTS}

Table 1. Demographic variable

\begin{tabular}{|l|l|}
\hline Mean age & $26.21 \pm 4.32$ Yrs \\
\hline Family history present & $34(34.00 \%)$ \\
\hline BMI & $25.32 \pm 2.38 \mathrm{Kg} / \mathrm{mt}^{2}$ \\
\hline
\end{tabular}

Mean age of patients was $26.21 \pm 4.32$ Yrs.

Table 2. Maternal complications among groups

\begin{tabular}{|l|l|}
\hline Polyhydramnios & $45(45.00 \%)$ \\
\hline Pre-term labor & $23(23.00 \%)$ \\
\hline Pre-eclampsia & $38(38.00 \%)$ \\
\hline APH & $5(5.00 \%)$ \\
\hline IUGR & $2(2.00 \%)$ \\
\hline PPH & $1(1.00 \%)$ \\
\hline Mean birth weight & $3.22 \pm 0.88 \mathrm{Kg}$ \\
\hline
\end{tabular}

Table 2 shows various maternal complications. $45 \%$ patients had polyhydramnios and $38 \%$ developed preeclampsia. Preterm labor was common in $23 \%$ of GDM patients.

\section{DISCUSSION}

Over past years studies have strongly indicated that untreated diabetes during pregnancy is associated with higher rates of maternal morbidity and mortality. 
The purpose of screening and management of DM is to prevent stillbirth, congenital anomalies, recurrent abortion, pre-eclampsia, intra uterine death and decrease incidence of macrosomic babies hence reducing maternal and perinatal morbidity and mortality.

The findings of the present study confirmed that DM patients are liable to have poor pregnancy outcomes.

Registered patients had regular antenatal visits and good glycemic control. Emergency patients had poor glycemic control leading to more maternal and fetal complications than registered patients. In present study mean birth weight $3.22 \pm 0.88 \mathrm{Kg}$. A study at Thomas B et al, shows $45.2 \%$ of babies are having birth weight between $2.6-3.9 \mathrm{~kg}$ and $8.1 \%$ babies had weight $\geq 4 \mathrm{~kg}$ indicating good glycemic control. ${ }^{5}$

Study from south India showed age $>25$ years is considered as a risk factor for GDM. ${ }^{6}$ In our study maximum no. of patients were of 20-29 years of age.

In present study family history were present in $34.00 \%$ cases, comparing with Di Cianni et al. reported that DM was more prevalent in women with positive family history. ${ }^{7}$ Yang et al. reported that pregnant women with a family history of diabetes in lst degree relatives had 2 fold increased risk of DM as compared to those without positive family history of diabetes in lst degree relatives. ${ }^{8}$

Several studies ${ }^{6,7}$ indicate a positive correlation between GDM and development of pre-eclampsia which was $38.00 \%$ in our study.

\section{CONCLUSION}

We concluded that proportion of pregnancy with diabetes was less, probably because universal screening was not feasible due to certain constrains and probably because of improvement in medical and obstetric care at secondary level fewer patients were referred to tertiary care hospital. Pregnancy with diabetes was more common in younger age group. Educating patients about regular antenatal care and proper monitoring of blood glucose level are important measures to reduce maternal and fetal complications. Universal screening and management by team approach of obstetrician, diabetologist, anaesthetist, physician, neonatologist can reduce fetal-neonatalmaternal morbidity and mortality associated with pregnancy with diabetes.

\section{REFERENCES}

1. Shingala KD, Shah SR, Vyas RC, Parikh PM. Fetomaternal outcome in patients with diabetes mellitus in pregnancy. Int J Reprod Contracept Obstet Gynecol 2019;8:2701-4

2. Williams JW, Cunningham FG, Leveno KJ, Bloom SL, Spong CY, Dashe JS Williams obstetrics. 25th Edition. New York: McGrow - Hill; 2018:1107.

3. O'sullivan JB, Mahan CM. Criteria for the oral glucose tolerance test in pregnancy. Diabetes. 1964;13:278-85

4. Landon MB, Mele L, Sc M, Spong CY, Carpenter MW, Ramin SM, et al. NIH Public Access. 2014;117:218-24

5. Thomas B. The prevalence, risk factors, maternal and fetal outcomes in gestational diabetes mellitus. Int J Drug Develop Res. 2012;4(3).

6. Seshiah V, Balaji V, Balaji MS, Paneerselvam A, Arthi T, Thamizharasi M, et al. Prevalence of gestational diabetes mellitus in South India (Tamil Nadu): a community based study. J Assoc Physicians India. 2008;56:329-33.

7. Di Cianni G Volpe L, Lencioni C, Miccoli R Cuccuru I Ghio A, et al. Prevalence and risk factors for gestational diabetes assessed by universal screening. Diabetes Res Clin Pract. 2003;62(2):131

8. Clausen TD, Mathiesen ER, Hansen T, Pedersen O, Jensen DM, Lauenborg J, et al. High prevalence of type 2 diabetes and pre-diabetes in adult offspring of women with gestational diabetes mellitus or type 1 diabetes: the role of intrauterine hyperglycemia. Diabetes Care. 2008;31(2):340-6 